\title{
Effect of intermediate layer in photocurrent improvement of three-layer photoanodes using WO3 and Fe2O3
}

\begin{abstract}
Sol-gel method was applied to synthesize WO3/Fe2O3 three-layer films in order to improve the generated photocurrent under UV-vis light irradiation. The films were deposited on FTO glass substrates through doctor bladding method. The samples were then calcined at $500{ }^{\circ} \mathrm{C}$. The photocurrents of the synthesized photoanodes were evaluated by measuring the electric current and voltage under UV-vis light at room temperature. Scanning electron microscopy (SEM) revealed unique surface morphologies owing to the presence of the intermediate layers. At an applied potential of $1300 \mathrm{mV}$, the WO3 $\mathrm{FF} 2 \mathrm{O} 3 \backslash \mathrm{WO} 3$ and $\mathrm{Fe} 2 \mathrm{O} 3 \backslash \mathrm{WO} 3 \backslash \mathrm{Fe} 2 \mathrm{O} 3$ photoanodes exhibited photocurrent densities up to $0.1 \mathrm{~mA} / \mathrm{cm} 2$ and $0.6 \mathrm{~mA} / \mathrm{cm} 2$, respectively. It was found that porous films with easy accessibility to the inner surface reveal high photocurrents. The intermediate layer of WO3 demonstrated higher values of photocurrent due to roughness enhancement on the upper surface with columnar tree-growth particles. However, a compact state was observed on the cross section of $\mathrm{Fe} 2 \mathrm{O} 3$ growth. A comparison was also drawn between the two and three-layer photoanodes using $\mathrm{Fe} 2 \mathrm{O} 3$ andWO3. The films were characterized by XRD, SEM/EDX, and UV-vis irradiation to determine the photocurrent densities.
\end{abstract}

Keyword: Photoanode; Multi-layer; Fe2O3; WO3 